\title{
Pancreatic Moderately Differentiated Ductal Adenocarcinoma
}

National Cancer Institute

\section{Source}

National Cancer Institute. Pancreatic Moderately Differentiated Ductal Adenocarcinoma.

NCI Thesaurus. Code C95427.

A pancreatic ductal adenocarcinoma characterized by the presence of medium-sized duct-like structures and small malignant tubular glandular structures. 